\title{
Analysis of Project Cost Control Based on Information Entropy and Gray Correlation
}

\author{
Wang Chunyan \\ Department of Civil Engineering of Hydropower \\ College of Science and Technology of China Three \\ Gorges University \\ Hubei, China \\ e-mail: 158176690@qq.com
}

\author{
Wei Ning \\ Electrical Room 3 \\ Hubei Special Equipment Inspection and Research \\ Institute \\ Hubei, China \\ e-mail: 8760669@qq.com
}

\begin{abstract}
How to determine the impact and quantitative comparison of various factors on the project cost has been a management problem. Based on the analysis of the project life cycle and the key influencing factors analysis, this paper sets up a grey relation analysis evaluation model, and calculates the grey incidence coefficient of each single factor; At the same time, apply the entropy to determine the influence of factors on the impact of the project cost, and calculate the weighted grey correlation degree. Finally, through the empirical this paper analysis and compare these engineering cost factors which have an important influence on engineering cost control. This can provide decision basis for the future management.
\end{abstract}

Keywords- Project Cost; Grey Relational Analysis; Correlation; Information Entropy; Combination weights

\section{INTRODUCTION}

The project cost is the engineering construction projects of investment in fixed assets, with long time, large investment, and characteristics of integrity. There are many factors in engineering construction in each stage of the project cost, which are interdependent between each other. The change of arbitrary factors will affect the stage and the whole project construction cost. Due to the diversity and variability of the influence factors, the influence degree to the engineering cost is not the same. The general managers can make a general evaluation so passive based on the experience of each influence factor. Therefore, the study for the construction of the entire life cycle of the influence factors is very necessary.

The research object of the grey system theory is "partial information known, part information unknown", "poor information" uncertain system. Through the generation of some known information, it can reach the development and implementation of the real world and exact description of cognitive [1]. From a small amount of information, the qualitative or fuzzy relation can be quantitative by the grey correlation analysis theory, which does not require so much information following some disciplinarian. Therefore with the information entropy and grey management analysis, this paper establishes the evaluation model and clarifies the factors to engineering cost through the grey relational analysis. Based on the weight of reference entropy principle it can eliminate the artificial subjective weight, and can overcome shortcomings of evaluation information poor on the other hand.

\section{FACTORS AFFECTING THE ENGINEERING COST}

For a construction project in the whole cycle, influence factors are so many. At present, different scholars have different views on the classification. Wei Daosheng [2] selects some such as the construction project cost budget, the cost of land, engineering change cost, design and management, the influence degree of various factors on the cost of the project; other scholars such as $\mathrm{Li}$ Yuejun [3], Liu Fang [4], from the construction project cost control in the whole course, study this relationship in the project decision-making stage, design stage, construction phase and completion phase of the project cost control, and give suggested factors and management of the impact on the various stages.

The author believes that the project cost influence factors are the following:

1)The cost of land

Land costs are high, and cannot be ignored occupying a large proportion in project cost. 2)The Quality of Design and Management ${ }^{[5]}$

Effective control of quality of engineering design is not only in relation to the number of the construction project investment, but also influences the economic benefits of the project after the delivery. The intrinsic quality of the design documents mainly depends on the design quality, which determines the level of advanced engineering and affects the project after the commissioning of economic benefits. Influence of design on project costs more than $75 \%$, and in the design phase of the project cost control it is the key to effective control of project cost.

\section{3)The Construction Drawing Budget}

Project implementation phase is a building entity formation stage, and the main stage which the human, material and financial resources are mainly consumed. To control the budget for construction drawing stage of cost, the key is to control the construction drawing budget.

4)Construction Organization Management ${ }^{[6]}$

Construction technology difficulty and method, as well as in the construction process of the rational 
management, have an important influence on the engineering quality, time limit for a project, schedule, and then influence the project the cost. For example, pay attention to the preparation work before construction, such as the technical personnel, mechanical equipment rational arrangement of the construction for the entire process.

5)Schedule

Schedule control is one of the three elements of engineering cost control, which has a direct impact on project cost. The length of time is directly related to the consumption of resources and human consumption.

\section{6)Engineering Change and Cost ${ }^{[7]}$}

In order to control the project cost, we should strictly control the project change occurs. Be strict site visa management and timely grasp project cost changes. Design change impacts on engineering cost is quite big, and the construction phase should be grasped the change project to control the cost.

\section{ESTABLISHMENT OF CONTROL MODEL}

\section{A. The Grey Relational Analysis Model}

According to the factors of each period between the $\mathrm{s}$ imilar degree of relevant statistical data, the grey relationa 1 analysis in grey system theory is to measure the degree o f correlation between factors, and to determine the degree of correlation between the factors of development trend ac cording to the similar degree of sequence curve geometr $y$ data factors of each period of grey correlation degree ${ }^{[8]}$. Namely it is used to describe the relationship among the $f$ actors.

The grey relational analysis is the development trend for the foothold, so it does not need much data with low re quirements of the distribution of samples, less amount of $\mathrm{c}$ alculation and analysis. The calculation process is as follo ws:

\section{1) Building Index}

With $\mathrm{n}$ representative works, the project $\operatorname{cost} \mathrm{X}_{0}$ as the characteristic sequence, the paper selects affecting factors land costs $\mathrm{X}_{1}$, design quality $\mathrm{X}_{2}$, emit construction drawing budget $\mathrm{X}_{3}$, duration $\mathrm{X}_{4}$, construction organization management $X_{5}$, engineering change cost $X_{6}$ as the comparative sequence. Sequence matrix table above can be written as follow.

$$
X=\left[\begin{array}{lllllll}
X_{01} & X_{02} & X_{03} & \ldots & X_{0 k} & \ldots & X_{0 n} \\
X_{11} & X_{12} & X_{13} & \ldots & X_{1 k} & \ldots & X_{1 n} \\
X_{21} & X_{22} & X_{23} & \ldots & X_{2 k} & \ldots & X_{2 n} \\
X_{31} & X_{32} & X_{33} & \ldots & X_{3 k} & \ldots & X_{3 n} \\
X_{41} & X_{42} & X_{43} & \ldots & X_{4 k} & \ldots & X_{4 n} \\
X_{51} & X_{52} & X_{53} & \ldots & X_{5 k} & \ldots & X_{5 n} \\
X_{61} & X_{62} & X_{63} & \ldots & X_{6 k} & \ldots & X_{6 n}
\end{array}\right]
$$

2) The Standard Treatment

Different indexes have different polarities, and have a different dimension. The index value is larger, not comparable, and be need for index dimensionless treatment, which is standardized. All the indicators are positive indicators, and numerical are $(0,1)$ interval. Standardization of methods is differential variation method, the effect measure variation method, the initial variation method and mean change method etc.

In this paper, the author adopts differential variation method, the formula is as follows:

$$
r_{i}(k)=\frac{X_{i}(k)-X_{\min }}{X_{\text {max }}-X_{\min }}
$$

In the type, $r_{i}(k)$ for the dimensionless data transformation; $\mathrm{Xi}(\mathrm{k})$ for each data in original data; Xmax and Xmin are original data sequence in the maximum and minimum values.

\section{3) The Gray Relational Coefficient Calculation}

Grey correlation coefficient are essentially two sequences compared in a specific environment of contacts, ranging from $(0,1)$.

The correlation coefficient is calculated by the following formula:

$$
\xi_{i j}=\frac{\Delta_{\min }+\rho \Delta_{\max }}{\Delta_{i}+\rho \Delta_{\max }}
$$

In the formula, Max, min, for the maximum and minimum value; $\rho$ for resolution ratio, generally between $0 \sim 1$, here to take $\rho=0.5$

4) Calculate the weighted grey correlation degree

$$
r_{i}=\sum_{j=1}^{n} w_{j} \xi_{i}(j)
$$

In the type, $\mathrm{W}_{\mathrm{j}}$ for the first $\mathrm{j}$ index weight. This pape $r$ adopts the objective law of the information entropy to de termine the indicators weight.

\section{B. To Determine the Weight of Indicators by the Information Entropy}

The concept of entropy in the dynamics is initially generated, using quantitative method to measure the uncertainty of an index. It is used to measure known valid information included in the data and determines the weight.The effective information of the indicators provides greater weight, the index should also be more big; Otherwise, and weight of the index should be smaller ${ }^{[9]}$. Therefore, this paper, according to the evaluation index value information provided, calculate the weight of every index entropy, by using information entropy.

1) With $m$ for the proposal to be assessed, $n$ for indicators, get standard treatment .

$$
\begin{array}{r}
X=\left(x_{i j}\right)_{m \times n}=\left[\begin{array}{cccc}
x_{11} & x_{12} & \ldots & x_{1 n} \\
x_{21} & x_{22} & \ldots & x_{2 n} \\
\ldots & \ldots & \ldots & \ldots \\
x_{m 1} & x_{m 2} & \ldots & x_{m n}
\end{array}\right] \\
(\mathrm{i}=1,2, . . \mathrm{m} ; \mathrm{j}=1,2, . . \mathrm{n})
\end{array}
$$

2) Calculate the $j$ index of the i evaluation value proportion, calculation formula: 


$$
f_{i j}=\frac{x_{i j}}{\sum_{i=0}^{m} x_{i j}}
$$

3) Calculate information entropy of the $j$ index

$$
H_{j}=-\frac{1}{\ln m} \sum_{i=1}^{m} f_{i j} \ln f_{i j}
$$

\section{THE EXAMPLE ANALYSIS}

\section{A. Original Data Collection}

According to the field investigation and consulting project information, select five construction project data, as shown in Table 1.

TABLE 1: FIVE PROJECTS COST DATA AND INFLUENCING FACTORS

\begin{tabular}{|c|c|c|c|c|c|}
\hline Index & 1 & 2 & 3 & 4 & 5 \\
\hline $\begin{array}{c}\text { Project Cost } \\
\mathrm{X}_{0} / \text { Million }\end{array}$ & 2200.00 & 18723.00 & 210.00 & 28357.00 & 1879.00 \\
\hline $\begin{array}{c}\text { Land Costs } \\
\mathrm{X}_{1} / \text { Million }\end{array}$ & 260.38 & 245.00 & 80.00 & 656.27 & 182.00 \\
\hline $\begin{array}{c}\text { Design Quality } \\
\mathrm{X}_{2}\end{array}$ & 91.00 & 89.00 & 90.00 & 92.00 & 88.00 \\
\hline $\begin{array}{c}\text { Construction } \\
\text { Drawing } \\
\text { Budget Price } \\
\mathrm{X}_{3} / \text { Million }\end{array}$ & 712.20 & 9587.65 & 72.00 & 19356.00 & 584.12 \\
\hline $\begin{array}{c}\text { Time limit } \mathrm{X}_{4} \\
\text { /Days }\end{array}$ & 520.00 & 690.00 & 385.00 & 1132.00 & 400.00 \\
\hline $\begin{array}{c}\text { Construction } \\
\text { Organization } \\
\text { Management } \\
\mathrm{X}_{5}\end{array}$ & 85.30 & 87.20 & 88.70 & 90.10 & 89.54 \\
\hline $\begin{array}{c}\text { Engineering } \\
\text { Change Cost } \\
\mathrm{X}_{6} / \text { Million }\end{array}$ & 49.98 & 56.23 & 21.68 & 67.50 & 35.69 \\
\hline
\end{tabular}

\section{B. Grey Relational Coefficient Calculation}

1) According to the formula (1) index are standardized, using differential variation methods. It is shown as Table 2.

\begin{tabular}{|c|c|c|c|c|c|}
\hline \multicolumn{1}{|c|}{ TABLE 2: THE STANDARDIZATION OF DATA } \\
\hline $\begin{array}{c}\text { Index } \\
\text { Project Cost } \\
\mathrm{X}_{0} / \text { Million }\end{array}$ & 0.0769 & 0.6600 & 0.0066 & 1.0000 & 0.0655 \\
\hline $\begin{array}{c}\text { Land Costs } \\
\mathrm{X}_{1} / \text { Million }\end{array}$ & 0.0084 & 0.0079 & 0.0021 & 0.0224 & 0.0057 \\
\hline $\begin{array}{c}\text { Design Quality } \\
\mathrm{X}_{2}\end{array}$ & 0.0024 & 0.0024 & 0.0024 & 0.0025 & 0.0023 \\
\hline $\begin{array}{c}\text { Construction } \\
\text { Drawing } \\
\text { Budget Price } \\
\mathrm{X}_{3} / \text { Million }\end{array}$ & 0.0244 & 0.3376 & 0.0018 & 0.6823 & 0.0198 \\
\hline $\begin{array}{c}\text { Time limit } \\
\text { /Days }\end{array}$ & 0.0176 & 0.0236 & 0.1282 & 0.0392 & 0.1985 \\
\hline $\begin{array}{c}\text { Construction } \\
\text { Organization } \\
\text { Management } \\
\mathrm{X}_{5}\end{array}$ & 0.0022 & 0.0023 & 0.0024 & 0.0024 & 0.0024 \\
\hline $\begin{array}{c}\text { Engineering } \\
\text { Change Cost } \\
\mathrm{X}_{6} / \text { Million }\end{array}$ & 0.0010 & 0.0014 & 0.0000 & 0.0016 & 0.0005 \\
\hline
\end{tabular}

2) Calculate the difference sequence and two range: From $\Delta=\left|X_{0}(k)-X_{i}(k)\right|, \quad$ get the features of each sequence and comparative sequence difference in Table 3.

TABLE 3: DifFerence SEQuence AND COMPARATIVE SEQuence

\begin{tabular}{|c|c|c|c|c|c|}
\hline $\begin{array}{c}\text { Difference } \\
\text { sequence }\end{array}$ & 1 & 2 & 3 & 4 & 5 \\
\hline$\Delta_{1}$ & 0.0685 & 0.6521 & 0.0045 & 0.9776 & 0.0598 \\
\hline$\Delta_{2}$ & 0.0745 & 0.6576 & 0.0042 & 0.9975 & 0.0632 \\
\hline$\Delta_{3}$ & 0.0525 & 0.3224 & 0.0048 & 0.3177 & 0.0457 \\
\hline$\Delta_{4}$ & 0.0593 & 0.6364 & 0.1216 & 0.9608 & 0.1330 \\
\hline$\Delta_{5}$ & 0.0747 & 0.6577 & 0.0042 & 0.9976 & 0.0631 \\
\hline$\Delta_{6}$ & 0.0759 & 0.6586 & 0.0066 & 0.9984 & 0.0650 \\
\hline
\end{tabular}

3) The gray relational coefficient calculation:

$$
\text { Using formula (2) to calculate }
$$

correlation coefficients in Table $4, \rho=0.5$ in this paper. TABLE 4: CORRELATION COEFFICIENT CHARACTERISTICS AND COMPARATIVE SEQUENCE

\begin{tabular}{|c|c|c|c|c|c|}
\hline$\xi_{i}(k)$ & 1 & 2 & 3 & 4 & 5 \\
\hline$\xi_{1}(k)$ & 0.8867 & 0.4372 & 0.9994 & 0.3409 & 0.9005 \\
\hline$\xi_{2}(k)$ & 0.8775 & 0.4352 & 1 & 0.3363 & 0.8951 \\
\hline$\xi_{3}(k)$ & 0.9125 & 0.6127 & 0.9988 & 0.6162 & 0.9238 \\
\hline$\xi_{4}(k)$ & 0.9013 & 0.4433 & 0.8109 & 0.3448 & 0.7963 \\
\hline$\xi_{5}(k)$ & 0.8772 & 0.4351 & 1 & 0.3363 & 0.8953 \\
\hline$\xi_{6}(k)$ & 0.8753 & 0.4348 & 0.9953 & 0.3477 & 0.8922 \\
\hline
\end{tabular}

C. Use the Information Entropy to Determine the Indicators Weight

1) Calculate the evaluation value proportion, according to the standard matrix and using the formula (4).

$F_{i j}=\left(f_{i j}\right)_{6 \times 5}=\left[\begin{array}{lllll}0.1515 & 0.0028 & 0.1204 & 0.0307 & 0.1320 \\ 0.0529 & 0.0083 & 0.1221 & 0.0043 & 0.0638 \\ 0.4143 & 0.8915 & 0.0976 & 0.9048 & 0.4238 \\ 0.3025 & 0.0642 & 0.5221 & 0.0529 & 0.2900 \\ 0.0496 & 0.0082 & 0.1203 & 0.0042 & 0.0649 \\ 0.0291 & 0.0052 & 0.0294 & 0.0032 & 0.0259\end{array}\right]$

2) Get available information entropy vector by the calculation formula (5).

$\mathrm{H}=(0.7927,0.2631,0.8018,0.2327,0.8024)$

3) Calculate the entropy index, using the calculation formula (6), and get available entropy vector.

$\mathrm{W}=(0.098,0.3497,0.094,0.3641,0.094)$

D. Calculation and order grey correlation degree

Using formula (3), to calculate the weighted related degree, available:

$\mathrm{R}=(0.5425,0.5386,0.6971,0.5196,0.5388$ ， $0.5410)$

$$
X_{3}>X_{1}>X_{6}>X_{5}>X_{2}>X_{4}
$$


That is

\section{E. Results of Analysis:}

1) From the correlation degree of factors influencing the ranking results, the construction drawing budget is the most critical factor affecting the project cost, which is consistent with the research results of Wei Daosheng ${ }^{[4]}$, Ma Zhili ${ }^{[10]}$ is. Therefore, the construction drawing budget on the degree of influence of different projects are almost always in the first row. The construction drawing budget is in the construction design stage, managers should carefully read the drawings, quota correctly, and try not to be rerun or missed.

2) The cost of land, engineering change and cost are ranked in the second and the third, being next only to the construction drawing budget, which has an important influence on the engineering cost. With the rapid development in recent years of real estate, land prices have rose so rapidly, and the land cost is a huge cost. For each project, engineering change may lead to engineering quantity changes, and may also lead to the engineering quality, nature or types changed. So that in order to control the project cost, the engineering cost changes should be strictly controlled. In the project decision-making stage, we should try to consider, as far as possible, the rare occurrence or non occurrence of engineering change.

3) Difficulty of construction and organization management, design quality, time limit, is ranked in fourth, fifth, and sixth. The design phase of the project cost control is the most important stage, and in order to make a more reasonable cost we must design budget estimate making. In the early stage of the project, although the design and management of the cost share is not high, the manager must carefully design scheme, design optimization, quota design, review design budgetary estimate, which have a positive effect on the control of construction cost. Both design methods and construction technology selection have an important effect on the whole process. Pay attention to the preparation work before construction, reasonable arrangement of time. Both a technical staff and mechanical equipment should be make rational arrangement of the construction in the entire process. Then pay attention to schedule for the equilibrium handle the relationship correctly, between the three project, quality and cost.

\section{CONCLUSION}

Gray correlation theory used in this article is to establish the evaluation model, using the information entropy of the index weights, and analysis and compares the effects of different factors on the project cost control. The quantitative of qualitative index improves the reliability and accuracy of the judgment. And through the example analysis result, the construction project managers have gotten a great reference value. From the analysis results manages can realize the targeted management, cost management, and improve management efficient.

\section{REFERENCES}

[1] Du dong,Pang Qinghua,Wuyan. Mordern Comprehensive Evaluation Method and Selected Case [M], Tsinghua University Press: Beijing, 2000:111-112.

[2] Wei Daosheng. Construction Cost Control Based on Grey Correlation Analysis, Journal of Chongqing Jiaotong University (Natural Science)[J], 2013, 32 (2),322 324.

[3] Li Yuejun, Chen Gang. Research on Control of Overall-Process Cost of Construction Project[J], Industrial Construction, 2010.(40)Supplement:1071-1075.

[4] Liu Fang, Zhang Yan. Overall Cost Management and Control of Construction Projects[J], Coal Technology, 2011(7):86-89.

[5] Hart, C.G., He, Z., An Advanced Cost Estimation Methodology for Engineering Systems[J], Systems Engineering, 2012, 15(1): 28-40.

[6] Ustundag A., Cevikcan E., Kilinc, M.S., Hybrid Fuzzy Risk Evaluation Model for Real Estate Investments[J], Journal of Multiple-Valued Logic and Soft Computing, 2011, 17(4): 339362.

[7] Mukaca, I.K., Sehic, D., Project Cost Control in Powe Engineering and Construction Company, Technics Technologies Education Management, 2010, 5(4): 740-748.

[8] Liu Lixuan, Based on multi-level fuzzy evaluation method of Inner Mongolia grid project post evaluation research [D].Nei Menggu,Inner Mongolia University of Science and Technology,2012.

[9] Zhu Saijing. Bid Evaluation Model of Construction Projects Based On Information Entropy and Grey Relevant, Analysis. Journal of Fujian University of Technology[J], 2012,10(6),579-582.

[10] MA Zhi-li,WU Kai-jun. Cost Control of Public Housing Based on Gray Correlation Analysis[J], Journal of Engineering Management, Vol. 2014,28 (1):118-122. 